\title{
A snapshot of students' blogging profiles in Taiwan: From the viewpoint of knowledge sharing
}

\author{
Ellis S.J. Fu
}

Department of Computer Science \& Information Engineering National Central University, Taiwan

E-mail: ellisfu@cc.ncu.edu.tw

\section{Stephen J.H. Yang*}

Department of Computer Science \& Information Engineering National Central University, Taiwan

E-mail: jhyang@csie.ncu.edu.tw

\section{Jeff J.S. Huang}

Department of Computer Science and Information Engineering Hwa Hsia Institute of Technology, Taiwan

E-mail: Jeff@cc.hwh.edu.tw

\section{*Corresponding author}

\begin{abstract}
In this era of Web 2.0, many young people are keeping blogs sharing their ideas, their feelings or their hobbies as a way of showing themselves. Taiwan, as a leading area of information technology, is not an exception. To explore the characteristics of blogging profiles of student bloggers in Taiwan, this study conducted a content analysis on a popular blog website. 157 student bloggers of three educational levels were recruited as participants. The results showed that there were both significant gender and educational level differences in knowledge sharing levels among participants, while blogroll links, posting categories, and blogging purposes also showed some interesting facts. These findings provide some insights of students' blogging and may give educators or sociologists some implications.
\end{abstract}

Keywords: Blog; Web 2.0; Knowledge sharing levels; Gender difference

Biographical notes: Ellis Sian-Jhih Fu received a bachelor's degree in mathematics from National Changhu University of Education, Taiwan, and a master's degree in Applied mathematics from National Chiao Tung University, Taiwan. He received his Ph.D. degree in Mathematics from National Central University, Taiwan. His research interest includes mathematical education and computer education.

Stephen J.H. Yang is the Distinguished Professor of Computer Science \& Information Engineering, and the Associate Dean of Academic Affairs at the National Central University, Taiwan. Dr. Yang received his PhD degree in Electrical Engineering \& Computer Science from the University of Illinois at Chicago in 1995. Dr. Yang has published over 60 journal papers, and received the 2010 outstanding research award from National Science Council, Taiwan. His research interests include creative learning, 3D virtual worlds, App 
software, and cloud services.

Jeff J.S. Huang received his $\mathrm{PhD}$ degree in Computer Science and Information Engineering from the National Central University at Taiwan in 2010. He is now an Assistant Professor of the Department of Computer Science and Information Engineering, Hwa Hsia Institute of technology, Taiwan. His research interests include e-Portfolio, e-learning, Web 2.0, CSCW, and CSCL.

\section{Introduction}

Since the prevalence of blogging in this era, blogs have been used as a tool to enhance learning and teaching in formal learning environments (Makri \& Kynigos, 2007; Fessakis, Tatsis, \& Dimitracopoulou, 2008; Churchill, 2009; Goh, Quek, \& Lee, 2010; Hsu \& Ching, 2011). However, the effects of using blogs in formal learning seem to have no consistent conclusions to date. For example, Nackerud and Scaletta (2008) conducted a survey of prevalent blogging trends in undergraduates to validate the learning benefits of blogging and held a positive attitude towards using blogs as a valuable communication tool in school. On the other side, Krause (2004) reported his experience in a writing class in which students seldom communicated through the course blog, with poor quality reflection upon the course materials in the blog content. Homik and Melis (2006) reported that students engaged in only a minimal level of blogging to meet assessment and typically focused on their own blog entry and lost the motivation to read those of their fellow students because it was essentially the same. It motivates our attempts to explore the blogging profiles of student bloggers and try to find some implications. On the other hand, since studies have shown some blogging trends in terms of age and sex like "men are somewhat more likely than women to create blogs" (Henning, 2003), "young adults and adolescents are more likely than other age groups to create blogs" (Huffaker \& Calvert, 2005), and "women use blogging as an outlet for creative work while men emphasis on information getting" (Pedersen \& Macafee, 2007). Therefore, we are curious about the correspondent phenomena in Taiwan.

$\mathrm{Du}$ and Wagner (2006) classified blogging tools into three features, namely, content presentation, content management, and social application. We adopted their ideas to explore the blogging profiles by these three facets. The content presentation facet was showed by the knowledge sharing levels and posting purposes, the content management facet by posting categories, and social application facet by blogroll links (the friends' blog links). More specifically, our research questions are the following:

1. Does gender difference a significant factor affect knowledge sharing levels?

2. Does educational level difference a significant factor affect knowledge sharing levels?

3. Does gender difference a significant factor affect blogroll links?

4. Does educational level difference a significant factor affect blogroll links?

5. Does gender difference a significant factor affect posting categories?

6. Does educational level difference a significant factor affect blogroll links?

7. What are the blogging purposes among these participants? 
These issues might help educators to learn more about students' blogging behavior, which might shed light on a blog-based learning or teaching. To achieve this goal, we conducted an empirical observation and content analysis of 157 bloggers of three different education levels, classified the posts according to the knowledge sharing levels, listed the blogging purposes, counted the posting categories and blogroll links, and then proposed some implications in the end.

\section{Methods}

The participants in this study were 157 student bloggers from Yahoo blog. We used an online questionnaire to invite students to join this study. The questionnaire contained several simple questions like "Are you a student?", "Are you a male or a female?", and "What's your educational level?". The bloggers' information was also checked from their blog content to confirm as effective samples. Blogging posts were analyzed from March 1, 2010 to February 28, 2011, while number of blogroll links, posting categories, and posting purposes were counted at February 28, 2011. Table 1 presents the basic information of these participants by gender and educational level. It contains 77 males and 80 females, which include 19 senior high school students, 102 undergraduates, and 36 graduates.

Table 1

Participant's distribution

\begin{tabular}{|l|l|l|}
\hline Gender & Number & Percentage \\
\hline Male & 77 & 49 \\
\hline Female & 80 & 51 \\
\hline \hline Educational level & Number & Percentage \\
\hline Senior High School students & $\begin{array}{l}19 \\
(10 \text { females, 9 males })\end{array}$ & 12.1 \\
\hline Undergraduates & $\begin{array}{l}102 \\
(54 \text { females, 48 males })\end{array}$ & 65 \\
\hline Graduates & $\begin{array}{l}36 \\
(16 \text { females, 20 males })\end{array}$ & 22.9 \\
\hline
\end{tabular}

The coding scheme for the knowledge sharing levels of our study was originally derived from the idea of Bloom's Taxonomy including knowledge, comprehension, application, analysis, synthesis, and evaluation. However, after browsing the data, we found that the first two levels, knowledge and comprehension, appeared most, while the other four showed just a few. Therefore, we combine the four levels as one. As a result, this research classified the bloggers' posts into three levels: the first level is sharing information; the second level is comparing or judging information; the third level is discussing information or applying information. The coding scheme is shown by Table 2 . These three levels are designed as indications of bloggers' knowledge sharing intensity. For example, a B3 post is higher than B2 post in knowledge sharing level for it involves more interaction and deep thoughts. 
Table 2

Abstract of coded knowledge sharing levels on blogs

\begin{tabular}{|c|c|c|}
\hline Code & Category & Explanation/examples \\
\hline B1 & Sharing information & $\begin{array}{l}\text { 1. Blog owner publishes personal opinions and } \\
\text { ideas of his life. } \\
\text { 2. Blog owner provides information for eating, } \\
\text { traveling, playing, or some coming events. } \\
\text { 3. Blog owner uploads multimedia files such as } \\
\text { video or audio. }\end{array}$ \\
\hline $\mathrm{B} 2$ & $\begin{array}{l}\text { Comparing or } \\
\text { judging information }\end{array}$ & $\begin{array}{l}\text { 1. Blog owner responds to comments with } \\
\text { different ideas but no succeeding discussion. } \\
\text { 2. Blog owner is affirmative to readers' } \\
\text { comments but no succeeding discussion. } \\
\text { 3. Blog owner seals the comments. }\end{array}$ \\
\hline B3 & $\begin{array}{l}\text { Discussing or } \\
\text { applying information }\end{array}$ & $\begin{array}{l}\text { 1. Blog owner and readers discuss some issue } \\
\text { through several reciprocal comments and do } \\
\text { not get a conclusion. } \\
\text { 2. Blog owner and readers discuss some issue } \\
\text { through several reciprocal comments and get } \\
\text { a conclusion. } \\
\text { 3. Blog owner quotes other bloggers' posts. }\end{array}$ \\
\hline
\end{tabular}

During the data collection, we found that some bloggers had a much larger amount of posts than other bloggers. This might violate normal distribution due to the heavy tail; thus, it is better to use the rank (order) as the basis of comparison. As a result, the Kruskal-Wallis one-way analysis of variance was adopted to examine the posting number differences between different educational levels and the Mann-Whitney $U$ test was adopted to examine gender differences in the number of posts, avoiding the bias due to some particularly large posting numbers.

\section{Results and discussion}

\subsection{Knowledge sharing levels}

The data showed that there were 6511 posts in B1, 7714 in B2, and 5854 in B3. On average, each blog contained 41.47 posts of B1, 49.13 of B2, and 37.29 of B3 as shown in Table 3. The number of B2 was larger than the numbers of B1 and B3, which means comparing or judging of information was the most popular activity in blogging. The amount $\mathrm{B} 3$ posts was the least showed a phenomenon that students did not do blogging involving discussion and application as they did in sharing and comparing information. However, the pooled data just roughly represent an initial image of the blogging profile. A more detailed analysis should be processed as following. 
Table 3

Counts of knowledge sharing levels

\begin{tabular}{|l|l|l|l|l|}
\hline & B1 & B2 & B3 & Total \\
\hline Quantity & 6511 & 7714 & 5854 & 20079 \\
\hline Average & 41.47 & 49.13 & 37.29 & 127.89 \\
\hline Percentage (\%) & $32.43 \%$ & $38.42 \%$ & $29.15 \%$ & $100 \%$ \\
\hline
\end{tabular}

\subsection{Gender and educational level effect on knowledge sharing levels}

Table 4 shows the details of the test result of gender effect in B1, B2 and B3 with MannWhitney $U$ test. It could be seen that, in general, females post more than males. There is a significant difference between males and females in B1, which means that female students significantly outperformed male students in number of B1 posts. Child and Agyeman-Budu (2010) claimed that bloggers who highly concerned about maintaining a positive self-presentation seem to blog more frequently than those who are less concerned or worried about maintaining a positive impression among others. It might have an inference that females are more concerned about self-presentation than males among our participants. Moreover, the research question 1 was been answered. The gender difference was a significant factor affect knowledge sharing levels.

Table 4

Mann-Whitney U test of gender difference in knowledge sharing levels

\begin{tabular}{|l|l|l|l|l|}
\hline & Gender & Mean rank & Z value & $\begin{array}{l}\text { P value } \\
\text { (double-tailed) }\end{array}$ \\
\hline B1 & Male & 71.24 & -2.10 & $0.036^{*}$ \\
\cline { 2 - 4 } & Female & 86.47 & -0.98 & \\
\hline B2 & Male & 75.40 & & 0.329 \\
\cline { 2 - 3 } & Female & 85.47 & -0.90 & 0.366 \\
\hline B3 & Male & 75.66 & & \\
\cline { 2 - 3 } & Female & 82.21 & & \\
\hline \multirow{2}{*}{$* 05$} & & & & \\
\hline
\end{tabular}

Table 5 shows the details of test result of educational level effect in B1, B2 and B3 with the Kruskal-Wallis one-way analysis of variance. It could be seen that there are significant differences between different educational levels in B2 and B3. The senior high school student bloggers post more than the others. More specifically, the result indicates that the higher educational level the lesser words. It might attribute the reason to that those graduates did not like the way to discuss ideas directly on blogs. Therefore, it might be important to consider educational level differences for designing blog-based learning environments. On the other hands, we also answered the research question 2 . The educational level difference was a significant factor affect knowledge sharing levels. 
Table 5

Analysis of variance for the posting numbers

\begin{tabular}{|l|l|l|l|l|}
\hline & Educational level & Mean rank & $\chi^{2}$-values, $\mathrm{df}=2$ & P value \\
\hline B1 & Senior High school students & 93.29 & 2.137 & 0.344 \\
& Undergraduates & 76.98 & & \\
\cline { 2 - 3 } & Graduates & 77.19 & & \\
\hline B2 & Senior High school students & 108.26 & 11.750 & $0.003 * *$ \\
\cline { 2 - 3 } & Undergraduates & 78.80 & & \\
\cline { 2 - 3 } & Graduates & 64.13 & & \\
\hline B3 & Senior High school students & 102.11 & 9.237 & $0.010^{*}$ \\
& Undergraduates & 80.19 & & \\
\cline { 2 - 3 } & Graduates & 64.43 & & \\
\hline$* p<.05, * * p<.01$ & & & \\
\hline
\end{tabular}

\subsection{Exploring the relations between the five variables}

In these section, the correlations of the five variables: B1, B2, B3, Br (number of blogroll links), and $\mathrm{Ca}$ (number of post categories) will be shown. By the methods mentioned in last section, we found that there is no significant effect by gender and educational level on the number of blogroll links and post categories. So, we list Table 5 and Table 6 for showing the profiles of these two characteristics. In Table 6, 1-9 means the number of blogroll links is from 1 to 9 and there are 18 bloggers have 1-9 blogroll links, which is $11.4 \%$ of the 157 bloggers. It should be noticed that there are 51 bloggers who did not list their blogroll links. It might be due to that they did not know how to use this tool or they just did not feel necessary about this tool.

Table 6

Number of bloggers' blogroll links

\begin{tabular}{|l|l|l|l|l|l|l|l|}
\hline $\begin{array}{l}\text { Number of } \\
\text { blogroll links } \\
(\mathrm{Br})\end{array}$ & 0 & $1-9$ & $10-19$ & $20-29$ & $30-39$ & $40-49$ & $50-$ \\
\hline $\begin{array}{l}\text { Blogger } \\
\text { count }\end{array}$ & 51 & 18 & 12 & 17 & 19 & 28 & 12 \\
\hline
\end{tabular}

$N=157$

Table 7 shows the number of categories bloggers created to classify their posts. In the Table, 1 means one category, that is, no classification is assigned to posts. More than $70 \%$ bloggers use 2-10 categories to classify their posts. 
Table 7

Number of bloggers' posting categories

\begin{tabular}{|l|l|l|l|l|l|l|}
\hline $\begin{array}{l}\text { Number of } \\
\text { categories } \\
\text { (Ca) }\end{array}$ & 1 & $2-5$ & $6-10$ & $11-15$ & $16-20$ & $21-25$ \\
\hline $\begin{array}{l}\text { Blogger } \\
\text { count }\end{array}$ & 37 & 61 & 50 & 5 & 1 & 3 \\
\hline
\end{tabular}

Table 8 shows the Pearson's correlation coefficient between the five variables. The number of blogroll links has a significant correlation with the numbers of B2 and B3 posts, while the number of categories has a significant correlation with the number of B1 posts. These are what we originally expected, since more blogroll links might imply the more social interaction and hence would involve more knowledge sharing activities. On the other hand, more posts need more categories if the blogger is care about content management. The correlations between B1, B2, and B3 are all significant as expected, since more topics attract more discussion. The correlation between number of categories and number of blogroll links is also significant shows some interesting things worth exploring.

Table 8

The Pearson's correlation coefficients of five variables

\begin{tabular}{|l|l|l|l|l|}
\hline & B2 & B3 & Br & Ca \\
\hline B1 & $0.287^{* *}$ & $0.277^{*}$ & 0.142 & $0.253^{* *}$ \\
\hline B2 & 1 & $0.971^{* *}$ & $0.203 * *$ & 0.092 \\
\hline B3 & & 1 & $0.209 * *$ & 0.078 \\
\hline Br & & & 1 & $0.164 *$ \\
\hline
\end{tabular}

To sum up, our results showed that the answers to the research questions 3-6 are all "no". Gender and educational level difference are not significant factors affecting the number of blogroll links and post categories among our participants.

\subsection{Blogging purposes}

In order to understand more of the blogging profiles of all participants, we investigated the main blogging purposes of all the 157 bloggers. The result of the content analysis shows that it could be divided into 7 kinds. They are

- $\quad$ sharing mood or feelings about current life (154/157),

- $\quad$ sharing traveling experience (67/157),

- $\quad$ sharing collection of special hobby (39/157),

- providing information for daily life (18/157),

- sharing reflection to school assignments (10/157), 
- $\quad$ keeping diary to practical training $(8 / 157)$, and

- creative writing (7/157).

Among these blogging purposes, the first one, sharing mood or feelings about current life, is the most. Almost all bloggers, 154 out of 157, post their articles for this kind. The second one, sharing traveling experience, is also popular that 67 bloggers having posts on this kind. The special hobby collection including lyrics, videos, records of sport contests, and pictures of movie stars, is the third popular one. The other kinds which the number of bloggers involving is under 20 may not be considered to be popular kinds. They are providing information for daily life, sharing reflection to school assignments, keeping diary to practical training. The last one, creative writing, means some novel writing or poem writing or some paintings made by bloggers.

Fullwood, Sheehan, and Nicholls (2009) conducted a content analysis of the MySpace (a popular blog site in the U.S.) and also list the blogging purposes of participates. Their list contained diary, advertising, information providing, information collection, media sharing, emotions sharing, and reporting. In the present study, the categories of blogging purposes are not far from these, although we focus on different group of participants. This suggests a general blogging phenomenon, no matter whether in different countries or for different age groups.

\section{Implications}

In light of the findings presented above, we propose the following implications:

1. Female student bloggers showed more knowledge sharing activities than males in the sense of posting more in each of knowledge sharing levels. Therefore, the educators should take into account the gender issue in conducting a blog-based learning environment.

2. The educational level effect on knowledge sharing levels is partly significant. However, it should be noted that the distribution of the participants in three educational levels is skew, since there are only $12 \%$ of high school students and $23 \%$ of graduates. It might not be suitable to give some inferences due to this result. However, the higher educational level the less words is a general phenomenon in schools of Taiwan.

3. In this study, the number of blogroll links was taken as an indication for representing the social interaction intensity of the bloggers, while the number of categories was taken as an indication for representing the posts management ability of the bloggers. However, there is no significant gender or educational level effect on these two variables. This might imply that the ability of social interaction and content management does not show significant difference among the participants.

4. The data showed that there were only 10 bloggers involving school work. This implies that to turn social media into learning tools is not so straight forward. Jones, Blackey, Fitzgibbon, and Chew (2010) suggested that educators should recognize the divide between "social" and "learning" and adopt social software that would support such divide. Thus, more studies on pedagogy of blog-based learning are needed. 


\section{Acknowledgements}

This work is supported by National Science Council, Taiwan under grants NSC98-2511S-008-006-MY3, NSC98-2511-S-008-007-MY3, NSC99-2511-S-008-006-MY3, and the Research Center for Science \& Technology for Learning of the University System of Taiwan.

\section{References}

Child, J. T., \& Agyeman-Budu, E. A. (2008). Blogging privacy management rule development: The impact of self-monitoring skills, concern for appropriateness, and blogging frequency. Computers in Human Behavior, 26(5), 957-963.

Churchill, D. (2009). Educational applications of Web 2.0: Using blogs to support teaching and learning. British Journal of Educational Technology, 40(1), 179-183.

Du, H. S., \& Wagner, C. (2006). Web success: Exploring the role of technology. International Journal of Human-Computer Studies, 64, 789-798.

Fessakis, G., Tatsis, K., \& Dimitracopoulou, A. (2008). Supporting "learning by design" activities using group blogs. Educational Technology \& Society, 11 (4), 199-212.

Fullwood, C., Sheehan, N., \& Nicholls, W. (2009). Blog function revisited: a content analysis of MySpace blogs. Cyberpsychology and Behavior, 12(6), 685-689.

Goh, J. W. P., Quek, C. J., \& Lee, O. K. (2010). An investigation of students' perceptions of learning benefits of weblogs in an east asian context: A rasch analysis. Educational Technology \& Society, 13(2), 90-101.

Henning, J. (2003). The blogging iceberg: of 4.12 million weblogs, most little seen and quickly abandoned. Brantree, MA: Perseus Development.

Homik, M., \& Melis, E. (2006). Using blogs for learning logs, proceedings of eportfolio. Oxford, UK.

Huffaker, D. A., \& Calvert, S. L. (2005). Gender, identity, and language use in teenage blogs. Journal of Computer-Mediated Communication, 10(2), article 1.

Hsu, Y.-C., \& Ching, Y.-H. (2011). Microblogging for strengthening a virtual learning community in an online course. Knowledge Management \& E-Learning: An international Journal, 3(4), 585-598.

Jones, N., Blackey, H., Fitzgibbon, K., \& Chew, E. (2010). Get out of MySpace! Computers \& Education, 54(3), 776-782.

Krause, S. D. (2004). When blogging goes bad: A cautionary tale about blogs, email lists, discussion, and interaction. Kairos, 9. Retrieved from http://english.ttu.edu/KAIROS/9.1/praxis/krause/index.html.

Makri, K., \& Kynigos, C. (2007). The role of blogs in studying the discourse and social practices of mathematics teachers. Educational Technology \& Society, 10 (1), 73-84.

Nackerud, S., \& Scaletta, K. (2008). Blogging in the academy. New Directions for Student Services, 124, 71-87.

Pedersen, S., \& Macafee, C. (2007). Gender differences in British blogging. Journal of Computer-Mediated Communication, 12(4), article 16. 